\title{
Imported cases of malaria in Spain: observational study using nationally reported statistics and surveillance data, 2002-2015
}

\author{
Zaida Herrador ${ }^{1,2^{*}+} \oplus$, Beatriz Fernández-Martinez ${ }^{3,4+}$, Víctor Quesada-Cubo ${ }^{5}$, Oliva Diaz-Garcia ${ }^{3}$, Rosa Cano ${ }^{3,4}$, \\ Agustín Benito ${ }^{1,2}$ and Diana Gómez-Barroso $0^{3,4}$
}

\begin{abstract}
Background: Malaria was eliminated in Spain in 1964. Since then, more than 10,000 cases of malaria have been reported, mostly in travellers and migrants, making it the most frequently imported disease into this country. In order to improve knowledge on imported malaria cases characteristics, the two main malaria data sources were assessed: the national surveillance system and the hospital discharge database (CMBD).
\end{abstract}

Methods: Observational study using prospectively gathered surveillance data and CMBD records between 2002 and 2015. The average number of hospitalizations per year was calculated to assess temporal patterns. Socio-demographic, clinical and travel background information were analysed. Bivariate and multivariable statistical methods were employed to evaluate hospitalization risk, fatal outcome, continent of infection and chemoprophylaxis failure and their association with different factors.

Results: A total of 9513 malaria hospital discharges and 7421 reported malaria cases were identified. The number of reported cases was below the number of hospitalizations during the whole study period, with a steady increase trend in both databases since 2008. Males aged 25-44 were the most represented in both data sources. Most frequent related co-diagnoses were anaemia (20.2\%) and thrombocytopaenia (15.4\%). The risks of fatal outcome increased with age and were associated with the parasite species (Plasmodium falciparum). The main place of infection was Africa (88.9\%), particularly Equatorial Guinea (33.2\%). Most reported cases were visiting friends and relatives (VFRs) and immigrants (70.2\%). A significant increased likelihood of hospitalization was observed for children under 10 years (aOR:2.7; 95\% Cl 1.9-3.9), those infected by Plasmodium vivax $(4.3 ; 95 \% \mathrm{Cl} 2.1-8.7)$ and travellers VFRs $(1.4 ; 95 \% \mathrm{Cl}$ 1.1-1.7). Only $4 \%$ of cases reported a correct regime of chemoprophylaxis. Being male, over 15 years, VFRs, migrant and born in an endemic country were associated to increased risk of failure in preventive chemotherapy.

Conclusions: The joint analysis of two data sources allowed for better characterization of imported malaria profile in Spain. Despite the availability of highly effective preventive measures, the preventable burden from malaria is high in Spain. Pre-travel advice and appropriately delivered preventive messages needs to be improved, particularly in migrants and VFRs.

Keywords: Malaria, Imported malaria, Malaria chemoprophylaxis, Non-endemic areas, Spain

\footnotetext{
*Correspondence: zherrador@isciii.es

${ }^{\dagger}$ Zaida Herrador and Beatriz Fernández-Martinez contributed equally to the work

${ }^{1}$ National Centre for Tropical Medicine, Health Institute Carlos III (ISCIII), 28029 Madrid, Spain

Full list of author information is available at the end of the article
} 


\section{Background}

According to the World Health Organization (WHO), between 2000 and 2015 there has been a 37\% global decrease in malaria incidence and a $60 \%$ decrease in global mortality rates [1]. Meantime, increasing travel to endemic areas in recent decades in association with the significant influx of immigrants from malaria-endemic countries has brought a steady increase in the number of imported cases in non-endemic countries [2].

Malaria poses a serious health hazard for travellers to areas of endemicity. Imported malaria refers to infections acquired outside and brought into a national territory [3]. Imported cases to non-endemic countries often result in delays in diagnosis, are expensive to treat, and can sometimes cause secondary local transmission [4]. In 2016, the European Region was the first in the world to have achieved interruption of indigenous malaria transmission. Still, malaria is the imported disease with the highest number of notifications in Europe [5]. It has been estimated that every year 10-15 million international travellers from Europe visit malaria endemic areas and $12,000-15,000$ cases of malaria are imported into the EU, with an average fatality rate of $0.4-3 \%$ [6]. The European Centre for Disease Prevention and Control (ECDC) coordinates this disease surveillance in the European Union (EU) and the member countries of the European Free Trade Association (EFTA). In 2015, the largest number of confirmed cases in this region was notified by France, followed by the UK and Spain (2500, 1397 and 706 cases, respectively) [7].

Spain was declared free of malaria in 1964. In the last decades, notified malaria infections have been mostly imported [8, 9]. Cases by autochthonous transmission have been scarce, and mainly related to health care (transfusion, transplants, parenteral or nosocomial), or vertical transmission. The cases of airport malaria have been anecdotal, and only 2 recent cases of malaria introduced by Plasmodium vivax have been documented [10]. Although there is a wide distribution of the potential vector of this species, it is considered that the current risk of introduced malaria is low [8]. Confirmed cases are monitored through the National Network of Epidemiological Surveillance (RENAVE in Spanish, Royal Decree 2210/1995) [11]. The last update of the malaria surveillance protocol was carried out in 2013 [12]. Other alternative source of information is the Centralized Hospital Discharge Database (CMBD in Spanish).

Reports have shown that knowledge on infectious disease prevention among departing travellers and the adherence of travellers to WHO and Centers for Disease Control and Prevention (CDC) recommendations is far from optimal [13]. In Spain, pre-travel consultation is voluntary (except for the yellow fever vaccination, which is mandatory at the entrance of several countries). Preventive measures and chemoprophylaxis against malaria follow the WHO recommendations, and depend on the travel destination, the duration of potential exposure, parasite resistance pattern, level and seasonality of transmission, age and pregnancy [14]. In order to improve knowledge on malaria imported cases characteristics, the epidemiological and clinical characteristics of patients diagnosed with malaria within the CMBD and the RENAVE databases were assessed. The hospitalization risk factors and the possible association between malaria chemoprophylaxis intake and gender, age or travel reason, among other factors, were also explored.

\section{Methods}

\section{Data source}

An epidemiological study using the CMBD and the RENAVE database for the time period January 1st, 2002 to December 31st, 2015 was performed.

\section{CMBD}

The CMBD database receives notification from around 98\% of the public hospitals in Spain [15]. The National Health System (NHS) provides free medical care to 99.5\% of the Spanish population, although those persons not covered by the NHS can be attended at the public hospitals. Private hospitals represent only a small proportion of all hospital admissions. Since 2005, CMBD also has a gradual coverage from private hospitals [16].

International Classification of Diseases, Ninth Revision, Clinical Modification (ICD-9CM), the ICD version employed during the study period, was used for this purpose [17]. Registers with ICD-9 CM "malaria" and "malaria complicating pregnancy childbirth or the puerperium" codes ("084."; "647.4") placed in any diagnostic position were analysed. The database was cleaned to remove any potential duplicates of hospitalizations. Sociodemographic and clinical data were collected. Relevant malaria related co-diagnoses were also explored.

\section{RENAVE}

Surveillance on malaria is comprehensive in Spain and based on aggregated and case-based notification. Case definition includes probable (patient who meet clinical criteria and with history of travel or permanence in an endemic area) and confirmed (+ laboratory confirmation by thick blood smear, detection of Plasmodium nucleic acid and/or a positive rapid diagnostic test). Regional public health authorities (autonomous regions) should report aggregated cases weekly and complete the reporting form information as soon as possible, using a standardized questionnaire [12]. Consistent individualized malaria data is available from 2002 on (and it is 
exhaustive at national level since 2014). Non-imported cases, which are notified urgently, were excluded for the analysis.

For each entry, socio-demographic, clinical and travel background information were analysed. Age was categorized in five groups: $0-15,16-24,25-34,35-44$ and $\geq 45$ years old. Place of birth and travel information were only available from RENAVE and includes place of birth and travel (country or continent when country is unknown), date and reason for travel (tourism, visiting friends and relatives (VFRs), work or being immigrantthis category includes people who had spent more than 1 year living in an endemic area, independently of their nationality).

\section{Statistical analysis}

The average number of hospitalizations per year was calculated in order to assess temporal patterns. Population figures of the Spanish municipalities were obtained from the Spanish National Statistics Institute [18] and were used as denominators for the study period, for both CMBD and RENAVE data.

Frequencies and percentages were used to summarize CMBD and RENAVE data. Differences in proportions were assessed by the $\chi^{2}$ test and 95\% confidence intervals ( $95 \% \mathrm{CI}$ ) were calculated. ANOVA was used to compare differences in means. Two-sided tests were used and $\mathrm{p}<0.05$ was considered significant.

Bivariate analyses for continent of infection, and relevant related factors were performed for RENAVE data. Bivariate analyses preceding logistic regression models for preventive chemotherapy (RENAVE), fatal outcome (CMBD and RENAVE) and hospitalization (RENAVE) were also carried out. Probable cases were excluded from the multivariate regression analysis, which were obtained by using a manual backward stepwise procedure. Age and gender, considered biologically relevant, and all variables associated with each of the outcomes at the $\mathrm{p}<0.10$ level were included in the multivariable analysis. The major assumptions of logistic regression analysis (absence of multicollinearity and interaction among independent variables) were checked to be satisfied. The goodness of fit was assessed using Hosmer-Lemeshow statistic. The adjusted odds ratio (aOR) and 95\% CI were computed. $\mathrm{p}$-values less than or equal to 0.05 were considered statistically significant. Data analysis was performed using STATA software version 14.

\section{Ethics statement}

This study involves the use of patient data from The Spanish Centralized Hospital Discharge Database (CMBD) and the RENAVE. CMBD data are hosted by the Ministry of Health, Consumption and Social Welfare
(MSCBS in Spanish). Researchers working in public and private institutions can request the databases by filling, signing and sending a questionnaire available at the MSCBS website. A signed Confidentiality Commitment is required in this questionnaire. All data are anonymized and de-identified by the MSCBS before it is provided to applicants. According to this Confidentiality Commitment signed with the MSCBS, researchers cannot provide the data to other researchers that must request the data directly to the MSCBS [15]. RENAVE data are registered through the national reporting electronic platform (SiViEs in Spanish) and hosted by the National Centre of Epidemiology. The so-called "SiViEs" computer platform was designed for epidemiological surveillance in Spain. It meets all legal and technical requirements concerning safe access and data protection. Formal ethical approval is not required for routine surveillance activities in Spain.

\section{Results}

A total of 9513 hospital discharges related to malaria (ICD-9-CM codes 123.*) and 7421 reported cases of malaria (6060 imported cases with individualized data) were identified for the 14-year study period. The number of reported cases was below the number of hospitalizations during the whole study period, although the difference between both records decreased over time (Fig. 1).

The most frequent isolated species of Plasmodium in both databases was Plasmodium falciparum. 26.7\% and $14.7 \%$ cases were non-specified malaria in CMBD and RENAVE, respectively ( $<<0.01$ ) (Fig. 2).

According to CMBD records, the mean age of the 9513 hospitalized patients was 31.9 years [interquartile range $(\mathrm{IQ})=23-41]$, being the $25-34$ and $35-44$ age groups the most represented. A total of $63.8 \%$ hospitalized were males, particularly predominating above 25 years old groups. There were 262 hospitalized women with pregnancy-associated malaria.

The majority (94.6\%) of malaria patients with known source of admission were admitted from emergency rooms. $95.8 \%$ of hospitalizations were discharged at home, death occurring in $0.8 \%$. The risk of fatal outcome increased with age (mean of 50.4 vs. 31.7 years old in exitus and non-exitus, respectively; aOR: 1.05; 95\% CI 1.031.07). The exitus outcome was also more frequent among those hospitalized with mixed malaria (aOR: 4.21 ; $95 \%$ CI 1.45-12.21). The hospitalization median time was 4 days (IQ range $=3-6$ ), with a median cost of $3995 €$ (Table 1).

Most frequent related co-diagnoses were anaemia (20.2\%, mostly iron deficiency anaemias and acquired and hereditary haemolytic anaemias), thrombocytopaenia (15.4\%; ICD-9-CM codes: $287.3-5)$, splenomegaly (2.4\%; ICD-9-CM code: 789.2) and hepatomegaly (1.5\%; ICD9-CM code: 789.3). Other frequent co-diagnoses were 


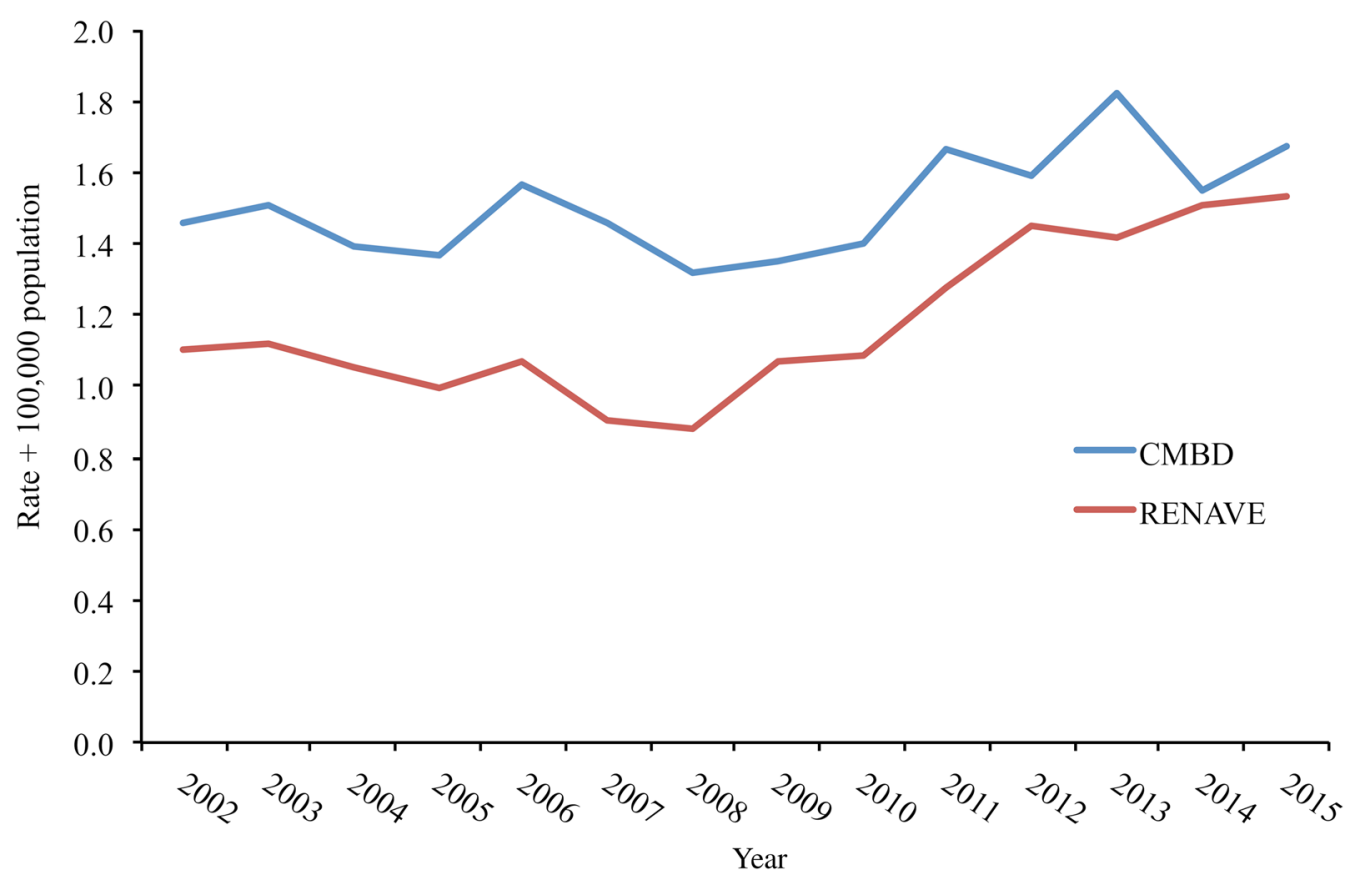

Fig. 1 Imported malaria incidence rates per 100,000 population based on CMBD and RENAVE records, Spain, 2002-2015. RENAVE data is based in individual case reports, except for one region. In this case, the number of cases per year were replaced by aggregated data. Starting from 2014 , RENAVE individualized data are comprehensive for the whole country

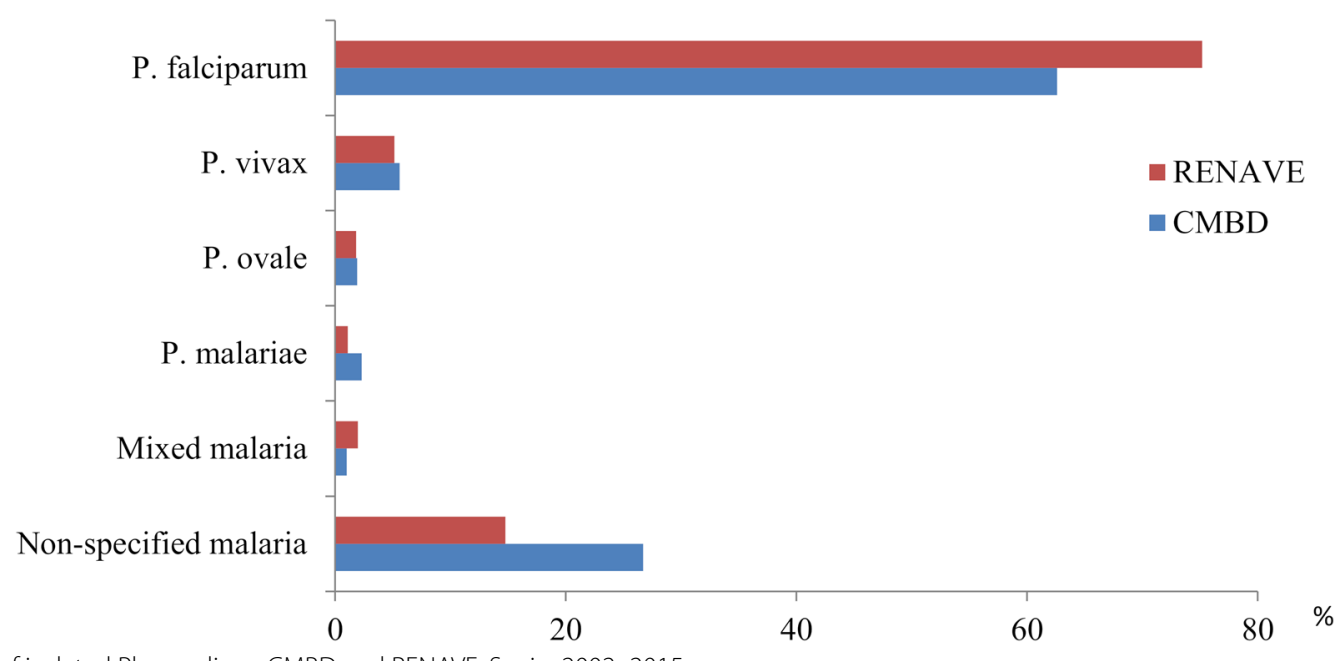

Fig. 2 Type of isolated Plasmodium, CMBD and RENAVE, Spain, 2002-2015

HIV (4.8\%; ICD-9-CM codes: 042, V08), acute kidney failure/non-specified (4.2\%; ICD-9-CM code: 584, 586) and helminthiases (3.1\%; ICD-9-CM code: 120-129).

In the RENAVE, epidemiological questionnaire were available for 6060 out of $7421(81.7 \%)$ reported cases of malaria. The $64.7 \%$ were males. The mean age was 32.6 (IQ range $=25-41$ ). More than $50 \%$ were between 25 and 45 years of age. The majority were born in a country other than Spain (66.2\%), being Africa the most frequent continent of birth (59.0\%). The main place of infection was Africa (88.9\%), particularly Equatorial Guinea (33.2\%). Most reported cases were VFRs and immigrants (70.2\%). Only $4 \%$ referred a correct regime of chemoprophylaxis (Table 2).

$74.8 \%$ of reported cases had required hospitalization. A significant increased likelihood of hospitalization was 
Table 1 Sociodemographic and clinical characteristics of malaria related hospitalizations, CMBD 2002-2015, Spain

\begin{tabular}{|c|c|c|}
\hline Variable & & n (\%) \\
\hline \multicolumn{3}{|l|}{ Gender } \\
\hline Male & & $6064(63.8)$ \\
\hline Female & & $3442(36.2)$ \\
\hline \multicolumn{3}{|l|}{ Age-groups (years) } \\
\hline$<15$ & & $1643(17.3)$ \\
\hline $15-24$ & & $991(10.4)$ \\
\hline $25-34$ & & $2739(28.8)$ \\
\hline $35-44$ & & $2329(24.5)$ \\
\hline$\geq 45$ & & 1810 19) \\
\hline \multicolumn{3}{|l|}{ Type of admission } \\
\hline Urgent & & 8998 (94.6) \\
\hline Programmed & & $507(5.3)$ \\
\hline Others/unknown & & $8(0.1)$ \\
\hline \multicolumn{3}{|l|}{ Type of discharge } \\
\hline Home & & $9113(95.8)$ \\
\hline Transfer & & $186(2)$ \\
\hline Voluntary discharge & & $110(1.2)$ \\
\hline Others/unknown & & $24(0.3)$ \\
\hline Exitus & & $80(0.8)$ \\
\hline \multicolumn{3}{|l|}{ Hospitalization time } \\
\hline$<1$ week & & $7154(75.2)$ \\
\hline \multirow[t]{2}{*}{$\geq 1$ week } & & $2359(24.8)$ \\
\hline & Mean & Median (IQ range) \\
\hline Age (years) & 31.9 & $33(23-41)$ \\
\hline Hospitalization time (days) & 5.9 & $4(3-6)$ \\
\hline Hospitalization cost (euro) & 4149.3 & $3994.9(3062-4296)$ \\
\hline
\end{tabular}

observed for children under 10 years (aOR: 2.7; 95\% CI 1.9-3.9), those infected by $P$. vivax (4.3; 95\% CI 2.1-8.7), mixed Plasmodium infections (aOR: 3.2; 95\% CI 1.4-7.5), P. falciparum (aOR: 3.1; 95\% CI 1.7-5.6), and Plasmodium ovale $(\mathrm{aOR}=2.3 ; 95 \% \mathrm{CI} 1.1-5.2)$, being Plasmodium malariae the reference category, and VFRs (1.4; 95\% CI 1.1-1.7) with respect to other travellers.

Fatal outcome was reported for 35 cases $(0.6 \%)$, from whom 30 were due to $P$. falciparum and 1 to mixed $P$. falciparum and $P$. ovale malaria, all infected in Africa (unknown species in 4 cases). The risk of fatal outcome increased with age (aOR: 1.04; 95\% CI 1.02-1.07) and for those born in Europe (5.4; 95\% CI 1.5-20.2), independently of the reason for travel.

In $95 \%$ of the records, the most likely continent of infection was supplied (Table 2). Gender distribution was similar for all the continents. Cases coming from Asia were significantly younger than those infected in other continents $(\mathrm{p}<0.01)$. More than a half of patients infected in Africa were VFRs, while there was a higher proportion of tourists among cases coming from America and Asia $(\mathrm{p}<0.01)$. Infections acquired in Asia and America were, for the greater part, caused by $P$. vivax $(78.5 \%$ and $61.1 \%$, respectively), whereas those acquired in Africa were mainly caused by P. falciparum (92.3\%) (Table 3 ).

Being male and older than 15 years old were associated to increased risk of failure in preventive chemotherapy (considering failure as none or non-complete preventive treatment) (Table 3). VFRs were 1.8 times more prompted to fail in malaria preventive chemotherapy than those travelling for work purposes. The risk was even higher for immigrants (aOR: 3.3; 95\% CI 2.2-4.9). Malaria cases born in endemic countries were at higher risk of failure in preventive chemotherapy (Table 4).

\section{Discussion}

Overall, a slight increase in the incidence rates of imported malaria during the study period was found in both databases. According to the WHO, there have been important gains in malaria control over the past two decades worldwide, although this progress has stalled in many countries in the most recent years [19]. In the European Region, 45 countries reported a decline in imported malaria cases and deaths between 2001 and 2010, possibly reflecting malaria control activities in endemic countries, an increase in the number of countries classified as malaria-free and/or and a possible under-reporting of cases [3]. Later on, at EU level the trend was upward until 2011, reduced in 2012 and again increased since 2013 [20]. Most probably, the difference in imported malaria trends in Spain with other European countries is explained by differences in the architecture of the air network, historical ties (in fact, the $22.3 \%$ of malaria reported cases in Spain were born in Equatorial Guinea, a former Spanish colony, and highly endemic to malaria [21]), sociodemographic characteristics of travellers, and malaria endemicity, among other factors $[13,19]$. On the other hand, this increase coincides with an increase in immigration figures in Spain, although this increase was halted in 2010 mainly due to the economic crisis [22], which would not explain the increase in reported cases and hospitalizations in the last years of study. Nevertheless, it should be taken into account that African immigrants' figures remained more or less constant during the economic crisis [22, 23].

The comparison of compulsory notified disease records with hospital records indicates a discrepancy between both registries, as already stated by other authors for other infectious diseases [24, 25]. Moreover, if it is assumed that not all malaria cases require hospitalization (74.8\% according to RENAVE figures), then the total 
Table 2 Characteristics of imported malaria cases (RENAVE), Spain, 2002-2015

\begin{tabular}{|c|c|}
\hline Variable & n (\%) \\
\hline \multicolumn{2}{|l|}{ Gender } \\
\hline Male & $3923(64.7)$ \\
\hline Female & $2106(34.8)$ \\
\hline Unknown & $31(0.5)$ \\
\hline \multicolumn{2}{|c|}{ Age-groups (years) } \\
\hline$<15$ & $865(14.3)$ \\
\hline $15-24$ & $596(9.8)$ \\
\hline $25-34$ & 1791 (29.6) \\
\hline $35-44$ & $1612(26.6)$ \\
\hline$\geq 45$ & $1148(18.9)$ \\
\hline Unknown & $48(0.8)$ \\
\hline \multicolumn{2}{|l|}{ Classification } \\
\hline Confirmed & $5850(96.5)$ \\
\hline Probable & $210(3.5)$ \\
\hline \multicolumn{2}{|c|}{ Hospitalization } \\
\hline No & $815(13.5)$ \\
\hline Yes & $4543(74.8)$ \\
\hline Unknown & $702(11.6)$ \\
\hline \multicolumn{2}{|l|}{ Exitus } \\
\hline No & $3872(63.9)$ \\
\hline Yes & $35(0.6)$ \\
\hline Unknown & $2153(35.5)$ \\
\hline \multicolumn{2}{|c|}{ Country of residence } \\
\hline Spain & $3972(65.6)$ \\
\hline Other & $365(6.0)$ \\
\hline Unknown & $1723(28.4)$ \\
\hline \multicolumn{2}{|l|}{ Place of birth } \\
\hline Spain & $1216(20.1)$ \\
\hline Other & $4010(66.2)$ \\
\hline Unknown & 834 (13.8) \\
\hline \multicolumn{2}{|c|}{ Continent of birth } \\
\hline Africa $^{a}$ & $3576(59.0)$ \\
\hline America & $150(2.5)$ \\
\hline Asia & $121(2.0)$ \\
\hline Oceania & $5(0.1)$ \\
\hline Europe & $1341(22.1)$ \\
\hline Unknown & $867(14.3)$ \\
\hline \multicolumn{2}{|l|}{ Travel reason } \\
\hline VFRs & $2770(45.7)$ \\
\hline Immigrant & $1482(24.5)$ \\
\hline Tourism & $610(10.1)$ \\
\hline Work & $695(11.5)$ \\
\hline Unknown & $503(8.3)$ \\
\hline \multicolumn{2}{|c|}{ Place of infection } \\
\hline Africa $^{\mathrm{b}}$ & $5389(88.9)$ \\
\hline America & $201(3.3)$ \\
\hline Asia & $154(2.5)$ \\
\hline Oceania & $14(0.2)$ \\
\hline Unknown & $302(5.0)$ \\
\hline
\end{tabular}

Table 2 (continued)

\begin{tabular}{lc}
\hline Variable & $\mathbf{n}(\%)$ \\
\hline Chemoprophylaxis & \\
None & $3020(49.8)$ \\
Non complete & $626(10.3)$ \\
Complete & $243(4.0)$ \\
Unknown & $2171(35.8)$
\end{tabular}

VFRs visiting friends and relatives

a 1349 (37.7\%) from Equatorial Guinea

b 2009 (37.3\%) from Equatorial Guinea

number of malaria cases occurring in Spain is even higher. Difficulties in reporting of imported malaria do not apply to Spain alone. Comparison of notified cases with hospital records have indicated a clear discrepancy in several countries [26, 27]. Nevertheless, this comparison should be read with caution, as the number of hospitalized malaria cases might be overrated due to readmissions and/or misclassification.

Among all malaria cases, the most frequent diagnosis was $P$. falciparum. The high prevalence of $P$. falciparum is in accordance with its well-documented relative virulence, the global prevalence of this species and also with other reports of imported malaria, mainly in patients returning from sub-Saharan Africa [1, 2, 28]. In the UK, this species accounted for about $70 \%$ of cases notified in 2011 , whereas $25 \%$ of cases were due to P. vivax [29, 30]. In Spain, the \% of imported cases due to $P$. vivax was quite lower, probably due to differences in travel destinations and immigrants' country of origin. On the other hand, a worthy of consideration number of reported cases and related hospitalizations miss microbiological information. An improvement in using complementary information from laboratory based surveillance system may resolve this problem as well as improve the surveillance performance.

In both databases, the distribution by gender and age group was similar. The proportion of malaria-related hospitalizations and case reporting was higher for males than females. Major risk of malaria among male travellers has been well documented [31]. Compared with women, men seem to be less likely to seek pre-travel advice, to adhere to appropriate personal vector avoidance and chemoprophylaxis, suffer more mosquito bites, and exhibit other high-risk behaviours [27, 32]. In fact, in this study the risk of failure in preventive chemotherapy was higher in males, result that support these hypotheses. The age distribution of malaria cases, which may reflect the age distribution of international travellers and immigrants or expatriates from endemic areas, is also consistent with previous reports $[6,28]$. 
Table 3 Characteristics of reported cases by continent of infection, RENAVE, Spain 2002-2015

\begin{tabular}{|c|c|c|c|c|c|c|c|c|c|}
\hline \multirow[t]{2}{*}{ Variables } & \multicolumn{2}{|c|}{ Africa $(n=5389)$} & \multicolumn{2}{|c|}{ America $(n=201)$} & \multicolumn{2}{|c|}{ Asia $(n=154)$} & \multicolumn{2}{|c|}{ Oceania $(n=14)$} & \multirow[t]{2}{*}{$p$ value } \\
\hline & $\mathbf{n}$ & $\%$ & $\mathrm{n}$ & $\%$ & $\mathbf{n}$ & $\%$ & $\mathrm{n}$ & $\%$ & \\
\hline \multicolumn{10}{|l|}{ Gender } \\
\hline Male & 3502 & 65.3 & 122 & 61.0 & 103 & 66.9 & 9 & 64.3 & \multirow[t]{2}{*}{ NS } \\
\hline Female & 1860 & 34.7 & 78 & 39.0 & 51 & 33.1 & 5 & 35.7 & \\
\hline \multicolumn{10}{|l|}{ Age group (years) } \\
\hline$<15$ & 781 & 14.6 & 9 & 4.5 & 31 & 20.4 & 0 & 0.0 & \multirow[t]{5}{*}{$<0.001$} \\
\hline $15-24$ & 504 & 9.4 & 32 & 16 & 28 & 18.4 & 1 & 7.1 & \\
\hline $25-34$ & 1566 & 29.2 & 82 & 41 & 46 & 30.3 & 3 & 21.4 & \\
\hline $35-44$ & 1475 & 27.5 & 42 & 21 & 23 & 15.1 & 7 & 50.0 & \\
\hline$\geq 45$ & 1030 & 19.2 & 35 & 17.5 & 24 & 15.8 & 3 & 21.4 & \\
\hline \multicolumn{10}{|l|}{ Continent of birth } \\
\hline Africa & 3571 & 74.1 & 0 & 0.0 & 2 & 1.4 & 0 & 0.0 & \multirow[t]{5}{*}{$<0.001$} \\
\hline America & 43 & 0.9 & 105 & 57.1 & 0 & 0.0 & 1 & 10.0 & \\
\hline Asia & 27 & 0.6 & 1 & 0.5 & 88 & 62.9 & 0 & 0.0 & \\
\hline Oceania & 3 & 0.1 & 0 & 0.0 & 0 & 0.0 & 2 & 20.0 & \\
\hline Europe & 1178 & 24.4 & 78 & 42.4 & 50 & 35.7 & 7 & 70.0 & \\
\hline \multicolumn{10}{|c|}{ Reason for travel or stay } \\
\hline Immigrant & 1360 & 26.4 & 64 & 32.8 & 42 & 30.2 & 3 & 25.0 & \multirow[t]{4}{*}{$<0.001$} \\
\hline Work & 654 & 12.7 & 19 & 9.7 & 10 & 7.2 & 3 & 25.0 & \\
\hline Tourism & 494 & 9.6 & 67 & 34.4 & 34 & 24.5 & 5 & 41.7 & \\
\hline VFRs & 2642 & 51.3 & 45 & 23.1 & 53 & 38.1 & 1 & 8.3 & \\
\hline \multicolumn{10}{|c|}{ Chemoprophylaxis } \\
\hline None & 3790 & 77.9 & 113 & 83.9 & 95 & 89.0 & 2 & 37.5 & \multirow[t]{3}{*}{$<0.001$} \\
\hline Non complete & 589 & 15.5 & 18 & 10.2 & 11 & 7.6 & 3 & 25.0 & \\
\hline Complete & 226 & 6.6 & 7 & 5.9 & 4 & 3.4 & 3 & 37.5 & \\
\hline \multicolumn{10}{|c|}{ Plasmodium species } \\
\hline P. falciparum & 4374 & 92.3 & 55 & 34.0 & 20 & 14.8 & 5 & 45.5 & \multirow[t]{5}{*}{$<0.001$} \\
\hline P. vivax & 92 & 1.9 & 99 & 61.1 & 106 & 78.5 & 5 & 45.5 & \\
\hline P.ovale & 102 & 2.2 & 0 & 0.0 & 5 & 3.7 & 1 & 9.1 & \\
\hline P. malariae & 57 & 1.2 & 3 & 1.9 & 3 & 2.2 & 0 & 0.0 & \\
\hline Mixed & 112 & 2.4 & 5 & 3.1 & 1 & 0.7 & 0 & 0.0 & \\
\hline \multicolumn{10}{|l|}{ Hospitalization } \\
\hline No & 736 & 15.0 & 28 & 15.5 & 12 & 8.3 & 0 & 0.0 & \multirow[t]{2}{*}{ NS $(p=0.076)$} \\
\hline Yes & 4180 & 85.0 & 153 & 84.5 & 132 & 91.7 & 11 & 100.0 & \\
\hline
\end{tabular}

The median hospitalization stay was below 5 days, and the rate of in hospital deaths and case-fatality was under $1 \%$. Available treatment regimens for malaria in most non-endemic countries are highly effective when properly and promptly administered, and symptoms can resolve within days [33]. The risk of hospitalization was higher for children under 10 years, while case fatality increased with age. Young children are at a higher risk of acquiring malaria abroad, while complicated disease occur more frequently at older ages [34]. P. vivax infection resulted in an increased risk of hospitalization. $P$. vivax infection, common in tropical countries in the Americas, Central and Southeast Asia, and Oceania [35], usually leads to milder disease and relapses. However, in recent years, many cases of severe malaria have been reported in $P$. vivax and $P$. knowlesi malaria. This seems to be related to travellers' non-immune status, no antimalarial prophylaxis intake (as travellers are less aware of malaria risk in these areas), delay in treatment, and severity of the illness at admission of travelers [36]. In fact, in this study the proportion of tourists among travellers returning from $P$. vivax endemic countries was higher than from other continents.

Death risk was higher among cases with mix infections and those infected with $P$. falciparum, which is consistent with the literature $[1,3,37]$. Interestingly, case fatality was higher for those born in Europe (5.4; 95\% CI 1.5-20.2), independently of the reason for travel. It is known that 
Table 4 Risk factors for failure in preventive chemotherapy, RENAVE, Spain 2002-2015

\begin{tabular}{lccr}
\hline Variables & aOR & $\mathbf{9 5 \% ~ C l}$ & p value \\
\hline Age group (ref:: $<$ 15 years) (years) & & \\
$15-24$ & 1.1 & $1.1-2.4$ & 0.009 \\
$25-34$ & 1.6 & $1.2-2.3$ & 0.001 \\
$35-44$ & 1.8 & $1.3-2.4$ & $<0.001$ \\
$45+$ & 1.5 & $1.1-2.1$ & 0.011 \\
Gender (ref:. female) & & & \\
Male & 1.3 & $1.1-1.6$ & 0.002 \\
Reason for travel or stay (ref:: work) & & $<0.001$ \\
Immigrant & 3.3 & $2.2-4.9$ & 0.040 \\
Tourism & 1.4 & $1.0-1.9$ & $<0.001$ \\
VFR & 1.8 & $1.3-2.5$ & \\
Born in malaria endemic country (ref.: no) & & $<0.001$ \\
Yes & 2.3 & $1.7-3.0$ & \\
\hline
\end{tabular}

a Countries endemic for malaria by 2015 [1]

malaria partial immunity in VFRs wanes with time resulting, especially after 12 years, in a more serious malaria clinical presentation $[6,38]$. Thus, it could have been expected that this group showed the highest fatality rate. Nevertheless, it should be taken into account that the overall fatality rate was fairly low for meaningful analysis.

More than a half reported cases were born in Africa, and travellers, VFRs and immigrants accounted for the majority of imported malaria cases, as documented in several studies $[28,39]$. Moreover, VFRs were less likely to report the use of any chemoprophylaxis. VFRs and immigrants from endemic countries are high risk groups for malaria due to their behavioral patterns and for geographical reason. The risk of infection vary, and is a function of several factors, including: the transmission intensity of the origin location; the activities undertaken in their visits; and prophylaxis availability and adherence $[4,40]$. Also importantly, these individuals may perceive themselves to be immune or at low risk, and may forego malaria prevention measures [27].

Malaria cases from Asia were significantly younger than those infected in other continents. A possible explanation might be that Asian migrants travel with their family members more frequently than migrants coming from Africa [41]. Moreover, there was a higher \% of tourists among cases coming from America and Asia. Although there is no risk of malaria in many tourist destinations in south-east Asia, the Caribbean and Latin America [1], malaria is still prevalent in other Southeast Asian and Latin American areas where large numbers of backpackers visit each year [3]. Furthermore, these travellers' risk perception might be low and thus affect the pre-travel health-seeking practices [42].
Overall, more than $60 \%$ of imported cases referred incomplete or none chemoprophylaxis. This \% was particularly high among VFRs and migrants. According to the $\mathrm{CDC}$, failure of prophylaxis may occur for at least three reasons. First, travellers may not seek or follow advice, or may receive inaccurate advice. Second, travellers may forget or not completely understand chemoprophylactic advice, or they may even be advised by peers not to use chemoprophylaxis. Third, general physicians infrequently provide pre-travel advice to patients and may not be aware of the current recommendations [43]. It is agreed that VFRs and immigrants are malaria risk groups requiring special attention $[2,27,31]$. Particularly, VFRs seem to be less inclined than other travellers to get pre-travel advice and to use chemoprophylaxis against malaria [13]. According to Scolari et al. in Italy, around $80 \%$ of migrants and VFRs do not have adequate information and do not take preventive measures during travel, although they are aware of the malaria risk in their origin countries [44]. In a recent qualitative study, it was observed that an important determinant that explained preventive behavior was the opinion that curing malaria is easier than using preventive tablets [45]. Moreover, recommendations for malaria chemoprophylaxis may often fail to address the cultural, social and economic needs of VFRs [46]. Finally, several studies in Spain found that migrants use health services differently from natives: they attend more frequently general practitioner (GP) practices and emergency rooms, especially those migrants from low-income countries $[47,48]$. This problem has been recently approached in UK, by approving the switch of anti-malarial from a prescription-only medicine to a pharmacy medicine [49]. In Spain, malaria chemoprophylaxis is considered to be as a medical physician competence. This measure may not be appropriate in this country for the following reasons (among others): (a) anti-malarial prescription might be accurately assessed if it is necessary or not, depending on the destination and type of travel. According to the traveller's profile and his/ her medical conditions, the appropriate drug and regimen would be decided. Otherwise, it might not be secure for travellers, creating scope to hasten the problem of antimicrobial immunity; (b) it may pose a challenge for the worldwide increase in antimicrobial resistance, and (c) Spanish pharmacists may not be prepared to give this kind of health advice, i.e. they do not have quick access to the latest information on what antimalarial is suitable to a given geography at a given time. In Spain, more suitable alternatives to improve malaria prevention in travellers may be: to reduce the price of prescribed anti-malarials; to make health services for immigrants and travellers (particularly VFRs) more readily available and adapted 
to these risk groups; and to improve and expand the pretravel advice at primary health care level.

\section{Limitations and conclusions}

This study has several limitations. Despite that two official databases (RENAVE and CMBD) were analysed, must probably the real burden of imported malaria in Spain is still underestimated. On one hand, hospital discharge records do not include cases managed in outpatient settings or asymptomatic cases, thus hospital records are still underestimating the real burden of malaria. Moreover, CMBD remains dependent by the population's health seeking behavior and healthcare accessibility [50]. On the other hand, underreporting of cases by national surveillance systems is common issue in Europe [4, 6]. It is important to address the constraints leading to underreporting, namely providing education and feedback to relevant health care workers on the importance of the notification process. Other limitation is the lack of denominator (overall number of travellers by origin and destination). Nevertheless, CMBD and RENAVE data are representative of the imported cases of Spain. Furthermore, it is the first time that both databases are analysed together in this particular issue.

Both analysed databases miss relevant information, such as personal and travel information, which may be useful to further explore and explain the raised hypotheses. These calls for the need to undertake further (qualitative and quantitative) investigations not only to substantiate these results but also to check new hypothesis which may have emerged.

This study confirms that the risk of imported malaria is higher in travellers from Africa, especially immigrants and VFRs, and that male and patients at the extremes of age constitute groups with increased risks. This study results also points that failure in preventive chemotherapy is still too common among imported malaria cases, particularly among those groups. All pre-travel advice needs to be individualized for each traveller, based on the traveller cultural background, exact travel route, season, and type of travel.

Finally, data on the features of imported cases can also provide valuable information about both the epidemiology of malaria in endemic regions, and on how malaria moves around the world. Moreover, with Anopheles vectors still present, imported cases can also cause secondary transmission in Spain, although the chances of resumption of endemic transmission are very small. This is mainly due to the fact that circulating anopheles in Spain are only competent for P. vivax [8]. Nevertheless, other Anopheles species might be reintroduced in the future. Thus, it should be highlighted the importance of vector and human cases surveillance for prevention of introduced malaria in non-endemic regions to avoid reemergence situations, as it recently occurred in Greece [7].

\begin{abstract}
Abbreviations
aOR: adjusted odds ratio; CDC: Centers for Disease Control and Prevention; CMBD: Centralized Hospital Discharge Database; CIBERESP: Consortium for Biomedical Research in Epidemiology and Public Health; ECDC: European Centre for Disease Prevention and Control; EFTA: European Free Trade Association; EU: European Union; IQ: interquartile range; ICD-9CM: International Classification of Diseases, Ninth Revision, Clinical Modification; MSCBS: Ministry of Health, Consumption and Social Welfare; NHS: National Health System; RENAVE: National Network of Epidemiological Surveillance; SiViEs: national reporting electronic platform; RICET: Network Biomedical Research on Tropical Diseases; OR: odds ratio; VFRs: visiting friends and relatives; WHO: World Health Organization.
\end{abstract}

\section{Acknowledgements}

We would like to acknowledge the contribution of all professionals participating in the Spanish Surveillance System (RENAVE) and the General Subdirection of the Institute for Health Information, Spanish Ministry of Health, Consumption and Social Welfare, for providing the information on which this study is based. Corresponding author's affiliation center belongs to the ISCIIISub. Gral. Redes Network Biomedical Research on Tropical Diseases (RICET in Spanish): RD12/0018/0001

\section{Authors' contributions}

$\mathrm{ZH}, \mathrm{BFM}, \mathrm{VQC}$ and DGB contributed to the conception and design of the study. ZH and BFM also carried the drafting of manuscript, statistical analysis, interpretation of data and revision. VQ and DGB contributed to design of the study, interpretation of data and revision of the manuscript. $A B, R C$ and ODG contributed to the conception of the study and revised critically the manuscript. All the authors read and approved the final manuscript.

\section{Funding}

This study has been funded by Instituto de Salud Carlos III through the project "PI15/01398" (Co-funded by European Regional Development Fund/European Social Fund "Investing in your future").

\section{Availability of data and materials}

This study involves the use of patient medical data from the Spanish Centralized Hospital Discharge Database (CMBD) (RENAVE). CMBD data are hosted by the Ministry of Health, Consumption and Social Welfare (MSCBS). Researchers working in public and private institutions can request the databases by filling, signing and sending a questionnaire available at the MSCBS website. In this questionnaire a signed Confidentiality Commitment is required. All data are anonymized and de-identified by the MSCBS before it is provided to applicants. According to this Confidentiality Commitment signed with the MSCBS, researchers cannot provide the data to other researchers that must request the data directly to the MSCBS in the following link: https://www.mscbs.gob. es/estadEstudios/estadisticas/estadisticas/estMinisterio/SolicitudCMBDdocs/ Formulario_Peticion_Datos_CMBD.pdf.

The RENAVE dataset is not publicly available due to restrictions imposed by National Epidemiological Surveillance Network, following a similar policy to other Public health Agencies, as the European Centre for Disease Control. The RENAVE, managed and maintained by the National Centre of Epidemiology, has the mandate to collect, analyse and disseminate surveillance data on infectious diseases in Spain. There is not direct access to the RENAVE database, but requests from third parties not belonging to the RENAVE with research purposes are solved by the National Centre of Epidemiology (http://www.iscii i.es/).

\section{Ethics approval and consent to participate}

This study involves the use of patient data from The Spanish Centralized Hospital Discharge Database (CMBD) and the RENAVE. CMBD data are hosted by the Ministry of Health, Consumption and Social Welfare (MSCBS in Spanish). RENAVE data are registered through the national reporting electronic platform 
(SiViEs in Spanish) and hosted by the National Centre of Epidemiology. Both datasets meets all legal and technical requirements concerning safe access and data protection. Formal ethical approval and individual consent is not required for routine surveillance activities in Spain.

\section{Consent for publication}

All the authors have read and approved the manuscript.

\section{Competing interests}

The authors declare that they have no competing interests.

\begin{abstract}
Author details
${ }^{1}$ National Centre for Tropical Medicine, Health Institute Carlos III (ISCIII), 28029 Madrid, Spain. ${ }^{2}$ Network Biomedical Research on Tropical Diseases (RICET in Spanish), Madrid, Spain. ${ }^{3}$ National Centre for Epidemiology, Instituto de Salud Carlos III (ISCIII), Madrid, Spain. ${ }^{4}$ Consortium for Biomedical Research in Epidemiology and Public Health (CIBERESP), Madrid, Spain. ${ }^{5}$ Hospital Universitario Gregorio Marañón, Madrid, Spain.
\end{abstract}

Received: 1 March 2019 Accepted: 3 July 2019

Published online: 10 July 2019

\section{References}

1. WHO. World malaria report 2015. Geneva: World Health Organization; 2015. http://www.who.int/malaria/media/world-malaria-report-2015/en/. Accessed 26 Sept 2018.

2. Jelinek T, Schulte C, Behrens R, Grobusch MP, Coulaud JP, Bisoffi Z, et al. Imported falciparum malaria in Europe: sentinel surveillance data from the European Network on Surveillance of Imported Infectious Diseases. Clin Infect Dis. 2002;34:572-6.

3. WHO. World malaria report 2011. Geneva: World Health Organization; 2012. http://www.who.int/malaria/publications/atoz/9789241564403/ en/. Accessed 22 Oct 2018.

4. Tatem AJ, Jia P, Ordanovich D, Falkner M, Huang Z, Howes R, et al. The geography of imported malaria to non-endemic countries: a meta-analysis of nationally reported statistics. Lancet Infect Dis. 2017;17:98-107.

5. WHO. History of malaria elimination in the European Region. Copenhagen: World Health Organization; 2016. http://www.euro.who.int/__data/ assets/pdf_file/0003/307272/Facsheet-malaria-elimination.pdf. Accessed 26 Sept 2018

6. Odolini S, Gautret P, Parola P. Epidemiology of imported malaria in the Mediterranean region. Mediterr J Hematol Infect Dis. 2012;4:e2012031.

7. European Centre for Disease Prevention and Control (ECDC). Annual epidemiological report for 2015; 2018. http://ecdc.europa.eu/en/publi cations-data/malaria-annual-epidemiological-report-2015. Accessed 27 Aug 2018.

8. Centro de Coordinación de Alertas y Emergencias sanitarias (CCAES), Ministerio de Sanidad SS e I. Informe de situación y evaluación del riesgo para España de Paludismo, 2015; 2015. http://www.mscbs.gob.es/profe sionales/saludPublica/ccayes/analisisituacion/doc/ER_paludismo_2015_ FINAL.pdf. Accessed 27 Aug 2018.

9. Fernández-Martinez, B, Díaz-García, O, Gómez-Barroso, D. Situación del paludismo en España. Evolución del tipo de notificación a la RENAVE y resumen de los resultados de la vigilancia de 2014 a 2017. Bol Epidemiol Sem 2019. http://revista.isciii.es/index.php/bes/article/view/1073/1328. Accessed 27 Aug 2018.

10. Velasco E, Gomez-Barroso D, Varela C, Diaz O, Cano R. Non-imported malaria in non-endemic countries: a review of cases in Spain. Malar J. 2017; $16: 260$.

11. Real Decreto $2210 / 1995$ por el que se crea la Red Nacional de Vigilancia Epidemiológica. BOE No. 21, 24.01.1996. http://www.boe.es/boe/ dias/1996/01/24/pdfs/A02153-02158.pdf. Accessed 28 Aug 2018.

12. Centro Nacional de Epidemiologia (CNE). Protocolo de vigilancia de paludismo; 2013. http://www.isciii.es/ISCIII/es/contenidos/fd-servi cios-cientifico-tecnicos/fd-vigilancias-alertas/fd-procedimientos/PROTO COLOS_RENAVE-ciber.pdf. Accessed 26 Sept 2018.

13. Lopez-Velez R, Bayas J. Spanish travelers to high-risk areas in the tropics: airport survey of travel health knowledge, attitudes, and practices in vaccination and malaria prevention. J Travel Med. 2007;14:297-305.
14. European Centre for Disease Prevention and Control (ECDC) 2018. https ://ecdc.europa.eu/en/malaria/facts/factsheet. Accessed 26 Sept 2018.

15. Ministerio de Sanidad, Servicios Sociales e lgualdad. Hospital Discharge Records in the National Health System. CMBD. http://www.msssi.gob.es/ en/estadEstudios/estadisticas/cmbdhome.htm. Accessed 10 Sept 2018.

16. Ministerio de Sanidad, Servicios Sociales e Igualdad. Explotación estadística del Conjunto Mínimo Básico de Datos Hospitalarios. Norma estatal 2012. Notas Metodológicas. https://www.msssi.gob.es/estadEstudios/ estadisticas/docs/NormaGRD2012/2012_norma_estatal_not_metod.pdf. Accessed 10 Sept 2018.

17. Centers for Disease Control and Prevention (U.S.) C for M\& MS (U. S). ICD9-CM international classification of diseases, ninth revision, clinical modification. U.S. Dept. of Health and Human Services, Centers for Disease Control and Prevention, Centers for Medicare and Medicaid Services: [U.S. G.P.O., Supt. Of Docs., distributor]; 2004.

18. Instituto Nacional de Estadística (INE). Official population figures of the Spanish Municipalities. 2016. http://www.ine.es/en/inebmenu/mnu_ padron_en.htm. Accessed 4 Jul 2018.

19. WHO. World malaria report 2018. Geneva: World Health Organization; 2018. http://apps.who.int/iris/bitstream/handle/10665/275867/97892 41565653-eng.pdf?ua=1. Accessed 19 Dec 2018.

20. European Centre for Disease Prevention and Control (ECDC). Surveillance Atlas of infectious diseases. https://ecdc.europa.eu/en/surveillance-atlas -infectious-diseases. Accessed 29 Jan 2019.

21. Ncogo P, Herrador Z, Romay-Barja M, García-Carrasco E, Nseng G, Berzosa $P$, et al. Malaria prevalence in Bata district, Equatorial Guinea: a crosssectional study. Malar J. 2015;14:456.

22. Instituto Nacional de Estadística (INE). Población extranjera por comunidades y provincias, nacionalidad y sexo. http://www.ine.es/jaxi/Tabla .htm?path=/t20/e245/p04/provi/l0/\&file=0ccaa002.px. Accessed 4 Dec 2017.

23. Cebrián JA, Bodega MI, Martín-Lou MA, Guajardo F. La crisis económica internacional y sus repercusiones en España y en su población inmigrante. Estud Geográficos. 2010;71:67-101.

24. Herrador Z, Siles-Lucas M, Aparicio P, Lopez-Velez R, Gherasim A, Garate T, et al. Cystic echinococcosis epidemiology in Spain based on hospitalization records, 1997-2012. PLoS Negl Trop Dis. 2016;10:e0004942.

25. Herrador Z, Fernandez-Martinez A, Gomez-Barroso D, León I, Vieira C, Muro A, et al. Mediterranean spotted fever in Spain, 1997-2014: epidemiological situation based on hospitalization records. PLoS ONE. 2017;12:e0174745.

26. Fonseca AG, Simões Dias S, Baptista JL, Torgal J. Surveillance of imported hospital requiring malaria in Portugal: can it be improved? Eur J Public Health. 2016;26:403-6.

27. Khuu D, Eberhard ML, Bristow BN, Javanbakht M, Ash LR, Shafir SC, et al. Malaria-related hospitalizations in the United States, 2000-2014. Am J Trop Med Hyg. 2017;97:213-21.

28. Norman FF, López-Polín A, Salvador F, Treviño B, Calabuig E, Torrús D, et al. Imported malaria in Spain (2009-2016): results from the +REDIVI Collaborative Network. Malar J. 2017;16:407.

29. Willcox ML, Mant J, O’Dempsey T. Imported malaria. BMJ. 2013;346:f3214.

30. Smith AD, Bradley DJ, Smith V, Blaze M, Behrens RH, Chiodini PL, et al. Imported malaria and high risk groups: observational study using UK surveillance data 1987-2006. BMJ. 2008;337:a120.

31. Askling HH, Nilsson J, Tegnell A, Janzon R, Ekdahl K. Malaria risk in travelers. Emerg Infect Dis. 2005;11:436-41.

32. Schlagenhauf $P$, Weld $L$, Goorhuis $A$, Gautret $P$, Weber $R$, von Sonnenburg F, et al. Travel-associated infection presenting in Europe (2008-12): an analysis of EuroTravNet longitudinal, surveillance data, and evaluation of the effect of the pre-travel consultation. Lancet Infect Dis. 2015;15:55-64

33. WHO. Guidelines for the treatment of malaria. Geneva: World Health Organization; 2015

34. Driessen GJ, Pereira RR, Brabin BJ, Hartwig NG. Imported malaria in children: a national surveillance in the Netherlands and a review of European studies. Eur J Public Health. 2007;18:184-8.

35. European Centre for Disease Prevention and Control (ECDC). Hospitalacquired malaria infections in the European Union; 2018. https://ecdc. europa.eu/en/publications-data/rapid-risk-assessment-hospital-acqui red-malaria-infections-european-union. Accessed 6 Jun 2019

36. World Health Organization. Severe malaria. Trop Med Int Health. 2014;19(Suppl 1):7-131. 
37. Checkley AM, Smith A, Smith V, Blaze M, Bradley D, Chiodini PL, et al. Risk factors for mortality from imported falciparum malaria in the United Kingdom over 20 years: an observational study. BMJ. 2012;344:e2116.

38. Mascarello M, Gobbi F, Angheben A, Concia E, Marocco S, Anselmi $M$, et al. Imported malaria in immigrants to Italy: a changing pattern observed in north eastern Italy. J Travel Med. 2009;16:317-21.

39. Leder K, Torresi J, Brownstein JS, Wilson ME, Keystone JS, Barnett E, et al. Travel-associated illness trends and clusters, 2000-2010. Emerg Infect Dis. 2013;19:1049.

40. Freedman DO, Weld LH, Kozarsky PE, Fisk T, Robins R, von Sonnenburg $F$, et al. Spectrum of disease and relation to place of exposure among ill returned travelers. N Engl J Med. 2006;354:119-30.

41. United Nations. International migration report 2017; 2017. http://www. un.org/en/development/desa/population/migration/publications/migra tionreport/docs/MigrationReport2017_Highlights.pdf. Accessed 29 Nov 2018.

42. Behrens RH, Carroll B, Hellgren U, Visser LG, Siikamäki H, Vestergaard LS, et al. The incidence of malaria in travellers to South-East Asia: is local malaria transmission a useful risk indicator? Malar J. 2010;9:266.

43. Centers for Disease Control and Prevention (CDC). Imported malaria and use of malaria chemoprophylaxis by travelers-Kentucky, Maryland, and United States, 1993-1994. MMWR Morb Mortal Wkly Rep. 1996;45:944-7.

44. Scolari C, Tedoldi S, Casalini C, Scarcella C, Matteelli A, Casari S, et al. Knowledge, attitudes, and practices on malaria preventive measures of migrants attending a public health clinic in northern Italy. J Travel Med. 2002;9:160-2
45. Wieten RW, Harting J, Biemond PM, Grobusch MP, van Vugt M. Towards improved uptake of malaria chemoprophylaxis among West African travellers: identification of behavioural determinants. Malar J. 2013;12:360.

46. Calleri G, Behrens RH, Schmid ML, Gobbi F, Grobusch MP, Castelli F, et al. Malaria chemoprophylaxis recommendations for immigrants to Europe, visiting relatives and friends-a Delphi method study. Malar J. 2011;10:137.

47. Graetz V, Rechel B, Groot W, Norredam M, Pavlova M. Utilization of health care services by migrants in Europe-a systematic literature review. $\mathrm{Br}$ Med Bull. 2017;121:5-18.

48. Regidor E, Sanz B, Pascual C, Lostao L, Sánchez E, Olalla JMD. La utilización de los servicios sanitarios por la población inmigrante en España. Gac Sanit. 2009;23:4-11.

49. Royal Pharmaceutical Society of Great Britain. Supply of anti-malarials as pharmacy medicines. https://www.rpharms.com/resources/quick-refer ence-guides/supply-of-anti-malarials-as-pharmacy-medicines. Accessed 6 Jun 2019.

50. Legido-Quigley H, Urdaneta E, Gonzalez A, La Parra D, Muntaner C, Alvarez-Dardet C, et al. Erosion of universal health coverage in Spain. Lancet. 2013;382:1977.

\section{Publisher's Note}

Springer Nature remains neutral with regard to jurisdictional claims in published maps and institutional affiliations.
Ready to submit your research? Choose BMC and benefit from:

- fast, convenient online submission

- thorough peer review by experienced researchers in your field

- rapid publication on acceptance

- support for research data, including large and complex data types

- gold Open Access which fosters wider collaboration and increased citations

- maximum visibility for your research: over $100 \mathrm{M}$ website views per year

At BMC, research is always in progress.

Learn more biomedcentral.com/submissions 